\title{
The use of visible and near infrared reflectance spectroscopy to predict beef $M$. longissimus thoracis et lumborum quality attributes
}

\author{
S. Andrés ${ }^{\text {a }}$, A. Silva ${ }^{\text {b }}$, A.L. Soares-Pereira ${ }^{\text {c }}$, C. Martins ${ }^{\text {b }}$, \\ A.M. Bruno-Soares ${ }^{\mathrm{c}, *}$, I. Murray \\ a Departamento de Producción Animal, Universidad de León, E-24071 León, Spain \\ ${ }^{\mathrm{b}}$ Universidade de Trás os Montes e Alto Douro (CECAV-UTAD), Ap. 1013, 5000-911 Vila Real, Portugal \\ ${ }^{\mathrm{c}}$ Instituto Superior de Agronomia (DPAA-ISA), Tapada da Ajuda, 1399 Lisboa Codex, Portugal \\ ${ }^{\mathrm{d}}$ Scottish Agriculture College (SAC), Ferguson Building, Craibstone Estate, Bucksburn, Aberdeen AB21 9YA, UK
}

Received 11 July 2006; received in revised form 17 May 2007; accepted 11 June 2007

\begin{abstract}
Visible and near infrared reflectance spectroscopy was used to predict $\mathrm{pH}$ at $24 \mathrm{~h}$ (pH24) post-mortem, sarcomere length (SL), cooking loss (CL), Warner-Bratzler Shear Force (WBSF) and colour parameters $\left(L^{*}, a^{*}, b^{*}\right)$ in beef cattle samples. Samples from $M$. longissimus thoracis et lumborum from 30 bulls were aged at $4{ }^{\circ} \mathrm{C}$ for $1,3,7$ and 14 days and analysed for pH, SL, CL, WBSF and colour. NIRS calibrations for $\mathrm{pH} 24$, luminosity at $0\left(L^{*} t 0\right)$ and $60 \mathrm{~min}\left(L^{*} t 60\right)$ showed good predictability $\left(R^{2}=0.97,0.85\right.$ and $0.82 ; \mathrm{SECV}=0.10$, $1.16,1.36$, respectively), whereas those related to the rest of the parameters were poorer.

(C) 2007 Elsevier Ltd. All rights reserved.
\end{abstract}

Keywords: Near infrared reflectance spectroscopy; Beef; Meat; Quality attributes

\section{Introduction}

Visible and near infrared reflectance spectroscopy (NIRS) is one of the most promising techniques for large-scale meat quality evaluation (Geesink et al., 2003). NIRS has the great potential of predicting quickly and accurately different attributes of meat quality, it allows rapid and frequent measurements, the sample preparation is fast and simple, is suitable for non-contact on-line use and for simultaneous determination of different attributes (Prevolnik, Candek-Potokar, \& Skorjanc, 2004).

The meat industry is an important economic sector in most developed countries as the demand for this product is high, especially as far as beef is concerned. It is well known that all the meat supplied to the markets must undergo quality controls in order to guarantee consumer

\footnotetext{
* Corresponding author. Tel.: +351 213653 407; fax: +351 213630734 . E-mail address: abs@isa.utl.pt (A.M. Bruno-Soares).
}

safety. However, some consumers are willing to pay higher prices for meat products with an additional guarantee of quality. For example, colour is one of the main factors influencing the sale of meat, since it is the only characteristic perceived by the consumer in the market. In addition, the eating quality of this product is highly determined by sensory properties such as tenderness, juiciness and flavour.

Regarding the application of reflectance spectroscopy to predict the meat quality, most attention has been focused on the estimation of tenderness (Rødbotten, Nilsen, \& Hildrum, 2000), drip loss (Geesink et al., 2003), colour (Leroy et al., 2003) and $\mathrm{pH}$ (Monin, 1998). $\mathrm{pH}$ is one of the most commonly measured parameters in meat, as it affects technological processing ability, keeping ability as well as most sensory traits (Monin, 1998). Thus early prediction of ultimate $\mathrm{pH}$ would be of interest to resolve problems of DFD (dark, firm and dry) and PSE (pale, soft and exudative) beef carcasses at the end of the slaughter line. 
Since NIRS is a rapid method, its use by the industry offers the ability to increase control checks during meat processing and retailing (Cozzolino, Barlocco, Vadell, Ballesteros, \& Gallieta, 2003).

The aim of this study was to examine the accuracy of visible/near infrared spectroscopy for the prediction of beef quality characteristics such as, $\mathrm{pH}$ at $24 \mathrm{~h}$ post-mortem (pH24), colour parameters $\left(L^{*}, a^{*}, b^{*}\right)$, sarcomere length (SL), cooking loss (CL) and Warner-Bratzler Shear Force (WBSF) using M. longissimus thoracis et lumborum of young Maronesa bulls.

\section{Materials and methods}

\subsection{Meat sampling}

Young Maronesa bulls $(n=30)$ aged between 9 and 11 months and with live weights ranging from 90 to $150 \mathrm{~kg}$, were slaughtered and selected according to the ultimate $\mathrm{pH}$ ( $\mathrm{pH}$ measured at $24 \mathrm{~h}$ post-mortem) in the M. longissimus thoracis et lumborum in order to obtain a wide range of $\mathrm{pH}$ values. This muscle was excised $24 \mathrm{~h}$ post-mortem from between the 8th rib and 2nd lumbar vertebra and divided into four parts. The first part was used for the laboratory procedures performed during the first day post-mortem and the three remaining pieces were vacuum packed and aged at $4{ }^{\circ} \mathrm{C}$ for 3,7 and 14 days post-mortem. For each aging time (1,3, 7 and 14 days post-mortem) 30 samples were used, 120 being the maximum number of samples analysed per parameter.

At the end of each period three slices were taken from each piece: the first one $(2.5 \mathrm{~cm}$ thick) was vacuum packed and stored at $-80^{\circ} \mathrm{C}$ for NIRS analysis, the second one ( $3 \mathrm{~cm}$ thick) was used for cooking loss and Warner-Bratzler Shear Force (WBSF) and the last one for colour and sarcomere length (SL) measurements.

\subsection{Technological analyses}

The $\mathrm{pH}$ of muscle samples was measured directly at 3 $(\mathrm{pH} 3 ; n=30)$ and $24 \mathrm{~h}(\mathrm{pH} 24 ; n=30)$ post-mortem using a combined glass electrode with a pH meter WTW PH 330.

Regarding the colour parameters, two measurements were taken at each of the four times post-mortem $(n=120)$; the first one was measured on a fresh meat cut $(n=30 ; 1$ day post-mortem) or, in the case of the aged meat $(n=90 ; 3,7$ and 14 days post-mortem), immediately after opening vacuum package $(t 0)$; the second one $(n=120 ; 1$, 3,7 and 14 days post-mortem) after keeping the meat in a tray covered with a polyethylene film at $4{ }^{\circ} \mathrm{C}$ during 60 min ( $t 60)$ to allow meat oxygenation ("blooming"). $L^{*}$ (luminosity), $a^{*}$ (coordinate green-red) and $b^{*}$ (coordinate blue-yellow) were determined with a Minolta Chromometer CR-310 (Minolta, Osaka, Japan).

Sarcomere length analyses were made only at day 7 postmortem $(n=30)$. In this case $4 \mathrm{~g}$ of meat were minced and homogenised at low speed $(8000 \mathrm{rpm})$ in a chilled $0.25 \mathrm{M}$ sucrose solution using an Ultra Turrax T25 mixer (Cross, West, \& Dutson, 1981). The length of 10 consecutive sarcomeres was measured (15 groups of 10 sarcomeres for each sample) under the phase contrast microscope $(40 \times$ objective) with a video camera attached and using the imageanalysing system Matrox Inspector (Matrox Electronic Systems Ltd., Dorval, Canada).

The water holding capacity of meat was evaluated by the cooking loss $(\mathrm{CL})$ method in each of the four time periods post-mortem $(n=120)$. Hence, the percentage of lost weight after cooking $\left(70{ }^{\circ} \mathrm{C}\right.$ in the core the meat) was determined (Silva, Patarata, \& Martins, 1999). After measurement of cooking loss, samples were stored overnight in a refrigerator and after reaching room temperature they were used for Warner-Bratzler Shear Force (WBSF) determination in the four time periods post-mortem $(n=120)$. The WBSF was measured on 10 sub-samples of $1 \mathrm{~cm}^{2}$ cross-section and about $4-5 \mathrm{~cm}$ length. The sub-samples fibres were positioned perpendicularly to the direction of the blade (driving at $100 \mathrm{~mm} \mathrm{~min}^{-1}$ ) attached to a Stevens QTS 25 Texture Analyzer (Stevens Advanced Weighing Systems Ltd., Great Dunmow, England).

\subsection{NIRS measurements}

\subsubsection{Sample preparation}

The frozen $\left(-80^{\circ} \mathrm{C}\right)$ meat samples were thawed in a fridge during $24 \mathrm{~h}$. Thereafter the samples were taken out, stored in a plastic bag to prevent water evaporation and left to reach room temperature. The surface temperature was recorded by an IR 'gun' (IRtec, Miniray 100, Eurotron) and digital colour photos of each sample were collected. Next, each sample was trimmed to eliminate connective tissue and two pieces of intact meat of $35 \mathrm{~mm}$ diameter were cut parallel to the longitudinal orientation of the muscle fibres (Cozzolino \& Murray, 2004) and placed inside $35 \mathrm{~mm}$ diameter quartz cuvette with aluminium foil backing. The duplicates were photographed inside the cuvette and scanned in order to obtain a mean spectrum for each sample.

\subsubsection{Spectra collection}

The diffuse reflectance spectra were collected at $2 \mathrm{~nm}$ intervals from 400 to $2498 \mathrm{~nm}$ (1050 data points per sample at 16 bit precision) using a NIRSystems 6500 scanning spectrophotometer (FOSS NIRSystems, Silver Spring, MD, USA) equipped with a spinning module, to increase the scanned sample area and reduce sampling error (Downey and Hildrum, 2004). Absorbance data were stored as $\log (1 / R), R$ being the reflectance. The instrument was operated by the software package NIRS2 version 3.01 (Infrasoft International, State College, PA, USA).

\subsubsection{Calibration and validation}

Calibration development and validation were performed using WinISI II version 1.02 (Infrasoft International, State College, PA, USA). Spectral data pre-treatments such as 
standard normal variation and detrending - SNV-D (Barnes, Dhanoa, \& Lister, 1989), multiplicative scatter correction - MSC - (Dhanoa, Lister, Sanderson, \& Barnes, $1994)$ and first or second order derivatives $(2,12,2,2)$ were applied to the spectra to reduce the noise and light scattering effects.

pH24 and SL parameters were predicted by using the spectra corresponding to the meat at day 1 post-mortem $(n=30)$. On the other hand, all the spectra $(n=120)$ were used to estimate colour parameters, CL and WBSF. Partial least squares regression (PLSR) was used to predict muscle properties using visible and near infrared spectra as independent variables. Two passes of elimination of outliers were allowed and full cross-validation was performed in order to avoid over-fitting the PLSR equations. The accuracy of prediction was given by the standard error of crossvalidation (SECV) and the ratio performance deviation RPD (Edney, Morgan, Williams, \& Campbell, 1994).

\section{Results and discussion}

\subsection{Analytical values}

Measurements of the technological parameters (Table 1) showed a wide range of variability, resulting from the aging of meat and the different ultimate $\mathrm{pH}$ reached by the samples. Moreover, it must be noted that in muscle samples $(n=30) \mathrm{pH} 24$ (5.99) was slightly lower than $\mathrm{pH} 3$ (6.66) as a consequence of the acidification during the post-mortem process. The ultimate $\mathrm{pH}$ of meat greatly affects meat quality. In fact, meat specimens with high $\mathrm{pH}$ values are darker, more susceptibility to bacterial spoilage, have reduced flavour but may have better water holding capacity and tenderness (Guignot, Touraille, Ouali, \& Renerre, 1994; Silva et al., 1999).

Cooking loss, measured as the percentage weight loss, showed a mean value of $9.53 \%$, thus much smaller than the $30.70 \%$ value measured at day 9 post-mortem by Leroy et al. (2003). This difference can be due to the high values of pH24 observed in the present study, which could have been

Table 1

Range, mean, standard deviation (SD) and coefficient of variation (CV) of the technological parameters of beef samples

\begin{tabular}{lrrccr}
\hline Parameter & \multicolumn{1}{c}{$n$} & Mean & Range & SD & CV $(\%)$ \\
\hline $\mathrm{pH} 3$ & 30 & 6.66 & $6.17-6.95$ & 0.20 & 2.93 \\
$\mathrm{pH} 24$ & 30 & 5.99 & $5.50-6.67$ & 0.33 & 5.53 \\
$\mathrm{CL}(\%)$ & 120 & 9.53 & $2.91-16.81$ & 3.07 & 32.18 \\
$L^{*} t 0$ & 120 & 35.03 & $27.62-42.70$ & 2.76 & 7.87 \\
$a^{*} t 0$ & 120 & 17.85 & $12.88-21.90$ & 1.36 & 7.60 \\
$b^{*} t 0$ & 120 & 2.94 & $0.88-5.59$ & 0.95 & 32.33 \\
$L^{*} t 60$ & 120 & 36.14 & $28.89-43.78$ & 3.76 & 10.40 \\
$a^{*} t 60$ & 120 & 20.23 & $15.23-26.40$ & 2.10 & 10.39 \\
$b^{*} t 60$ & 120 & 6.56 & $2.96-11.37$ & 1.77 & 26.92 \\
SL $(\mu \mathrm{m})$ & 30 & 1.70 & $1.51-1.84$ & 0.09 & 5.06 \\
WBSF $\left(\mathrm{kg} \mathrm{cm}^{-2}\right)$ & 120 & 10.37 & $3.85-19.88$ & 3.84 & 37.01 \\
\hline
\end{tabular}

$n$ : number of samples; SD: standard deviation; $\mathrm{CV}$ : coefficient of variation. partially responsible for the superior water holding capacity measured.

The colour parameters showed substantial variation, maybe as a result of the range observed in the ultimate $\mathrm{pH}$, which exerts a marked effect on meat colour. Meat oxygenation and oxymyoglobin formation after $60 \mathrm{~min}$ was the reason why the $a^{*}$ and $b^{*}$ parameters at $t 60$ showed higher values than at $t 0$.

SL is a measurement of muscle shortening during rigor mortis development and affects meat quality, mainly tenderness (Tornberg, 1996). Considering $2.00 \mu \mathrm{m}$ as the length of the relaxed sarcomere (Quali, Lepetit, Touraille, \& Kopp, 1994), the values observed in this study $(1.51-1.8 \mu \mathrm{m})$, correspond to about $25 \%$ shortening.

WBSF showed a mean value of $10.37 \mathrm{~kg} \mathrm{~cm}^{-2}$ with a higher coefficient of variation $(37.01 \%)$. This variation could be mainly due to the aging time, ultimate $\mathrm{pH}$ and possible effect of sarcomere length. Moreover the magnitude of this parameter decreased as the aging process progressed (Table 2).

\subsection{Observations on near infrared spectra}

\subsubsection{Absorbance spectra $(\log (1 / R))$}

Fig. 1 shows the mean spectra corresponding to each group of samples (meat samples at 1, 3, 7 and 14 days post-mortem). No significant differences could be observed between these mean spectra. In addition, when principal components analysis (PCA) was performed on all the spectra $(n=120)$, the scores corresponding to each sample showed no differences between different groups of samples (Fig. 2). In other words, apparently no differences due to the aging process could be observed in meat samples by NIRS, despite the differences observed by analytical values (Table 2).

Regarding the mean spectra (Fig. 1) two main broad bands can be identified in the visible region $(400-750 \mathrm{~nm})$ at $435,575 \mathrm{~nm}$, and five more bands in the near infrared area $(750-2500 \mathrm{~nm})$ around $760,980,1200,1450$, and $1950 \mathrm{~nm}$. The absorption band at $435 \mathrm{~nm}$ is the Soret band attributed to an intense $\pi \rightarrow \pi^{*}$ transition observed in all conjugated porphyrin (macrocyclic tetrapyrrole) rings in which electron delocalisation extends throughout the macrocyclic ring (e.g. the haem prosthetic group in myoglobin $\mathrm{Mb}$ ). The spectral features in the visible region are very similar to those reported by Barlocco, Vadell, Ballesteros, Gallieta, and Cozzolino (2006), Cozzolino et al. (2003) and Swatland (1995) in pork meat samples and by Cozzolino and Murray (2004) in beef, pork and chicken meat samples, since all these species contain the same primary pigment responsible for meat colour, myoglobin.

A weak near infrared band at $760 \mathrm{~nm}$ can be due to the $\mathrm{OH}$ third overtone or an absorption band produced by myoglobin oxidation (Cozzolino \& Murray, 2004; Liu et al., 2003). Moreover, characteristic bands of water were identified at $980 \mathrm{~nm}(\mathrm{OH}$ second overtone), $1450 \mathrm{~nm}(\mathrm{OH}$ first overtone), and $1950 \mathrm{~nm}$ ( $\mathrm{OH}$ combination band) 
Table 2

Mean and standard deviation (SD) of the technological parameters of beef samples with different aging days

\begin{tabular}{|c|c|c|c|c|c|c|c|c|}
\hline \multirow[t]{2}{*}{ Parameter } & \multicolumn{2}{|c|}{$\begin{array}{l}1 \text { day } \\
\text { Post-mortem }\end{array}$} & \multicolumn{2}{|c|}{$\begin{array}{l}3 \text { days } \\
\text { Post-mortem }\end{array}$} & \multicolumn{2}{|c|}{$\begin{array}{l}7 \text { days } \\
\text { Post-mortem }\end{array}$} & \multicolumn{2}{|c|}{$\begin{array}{l}14 \text { days } \\
\text { Post-mortem }\end{array}$} \\
\hline & Mean & $\mathrm{SD}$ & Mean & $\mathrm{SD}$ & Mean & $\mathrm{SD}$ & Mean & SD \\
\hline CL $(\%)$ & 9.29 & 2.74 & 9.39 & 2.86 & 9.07 & 3.03 & 10.35 & 3.58 \\
\hline$L^{*} t 0$ & 33.57 & 2.15 & 34.80 & 2.48 & 35.59 & 2.81 & 36.19 & 2.89 \\
\hline$a^{*} t 0$ & 17.16 & 1.26 & 17.65 & 1.44 & 18.20 & 1.31 & 18.38 & 1.10 \\
\hline$b^{*} t 0$ & 2.25 & 0.68 & 2.71 & 0.87 & 3.52 & 1.01 & 3.28 & 0.68 \\
\hline$L^{*} t 60$ & 34.61 & 2.27 & 36.45 & 2.32 & 37.26 & 2.97 & 37.24 & 3.37 \\
\hline$a^{*} t 60$ & 19.03 & 1.46 & 20.04 & 1.56 & 20.78 & 2.22 & 21.06 & 2.47 \\
\hline$b^{*} t 60$ & 5.44 & 1.05 & 6.57 & 1.11 & 7.12 & 1.89 & 7.09 & 2.23 \\
\hline WBSF $\left(\mathrm{kg} \mathrm{cm}^{-2}\right)$ & 13.42 & 3.34 & 10.22 & 3.22 & 9.23 & 3.66 & 8.60 & 3.36 \\
\hline
\end{tabular}

SD: standard deviation.

* Number of samples $=30$.

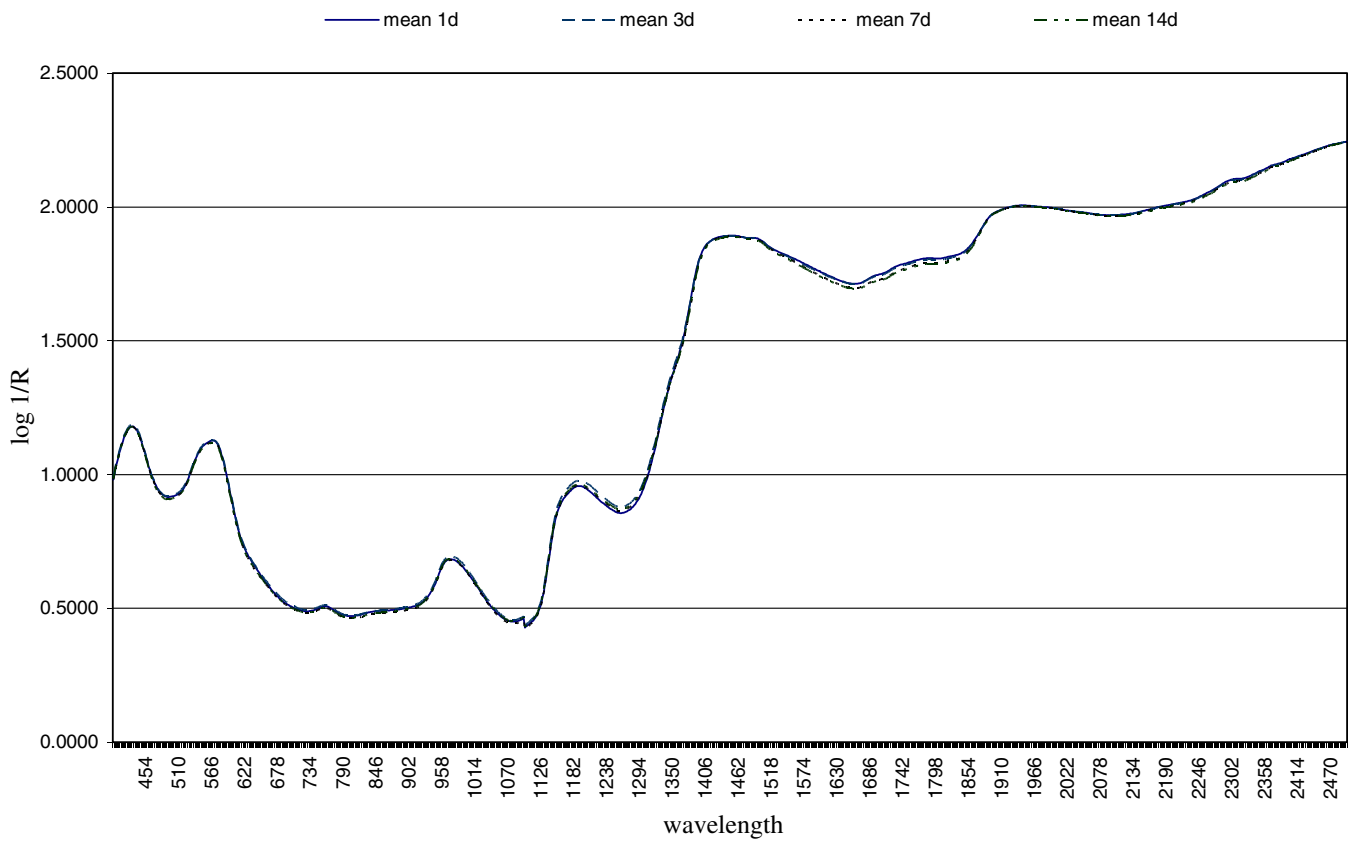

Fig. 1. Four mean spectra corresponding to the four meat sample groups $(1,3,7$ and 14 days post-mortem, $n=120)$.

(Cozzolino \& Murray, 2004; Cozzolino et al., 2003; Leroy et al., 2003).Water is the main component of meat samples, typically $74 \%$ in lean beef, thus explaining the water bands previously mentioned (Cozzolino \& Murray, 2004). A band around $1200 \mathrm{~nm}$ (CH second overtone) can be attributed to fat content (Cozzolino \& Murray, 2004; Leroy et al., 2003; Rødbotten et al., 2000).

\subsubsection{Prediction of the technological characteristics of the meat samples}

According to Prevolnik et al. (2004) there have been no successful attempts to estimate $\mathrm{pH}$ values. However in the present study absorbance data of meat samples at day 1 post-mortem $(n=30)$ showed good correlations with pH24 (Fig. 3). We found that this parameter (Table 3) could be accurately predicted by NIRS $\left(R^{2}=0.97\right.$, $\mathrm{RPD}=3.17)$. Light scattering properties of muscle tissue are well known to be affected by tissue $\mathrm{pH}$ (Swatland,
1995), so this may well explain how the ultimate $\mathrm{pH}$ could have been accurately predicted by visible and near infrared reflectance spectroscopy (Fig. 4). The good repeatability of the reference method in the present study (SEL pH24 = 0.10 ) could also have contributed partially to the successful prediction of $\mathrm{pH} 24$ obtained by NIRS. In addition, it does not seem probable that this equation has been over-fitted (number of PLS factors in the equation, $p=3$ ) as a consequence of the small population $(n=30)$, since there was a high correlation observed between the absorbance data and $\mathrm{pH} 24$ (Fig. 3).

The prediction of $\mathrm{pH} 24$ using NIRS technology was also possible when all the samples having different aging times $(n=120)$ were included in the calibration set (data not shown). Success arises probably as a result of the stability of $\mathrm{pH} 24$ (also known as ultimate $\mathrm{pH}$ ) during the aging process, value that did not change significantly on longer maturation. 


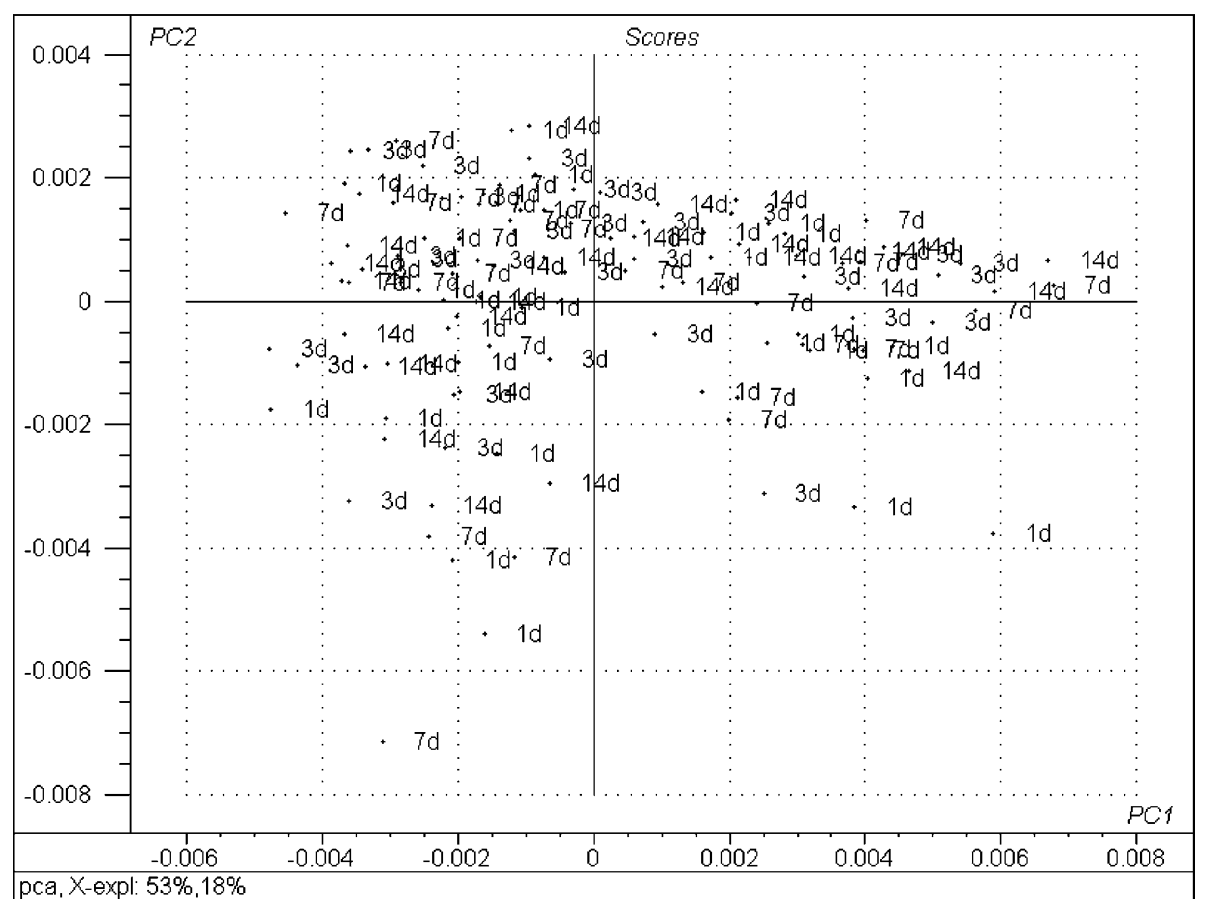

Fig. 2. PCA scores corresponding to the four meat sample groups (1, 3, 7 and 14 days post-mortem, $n=120)$.

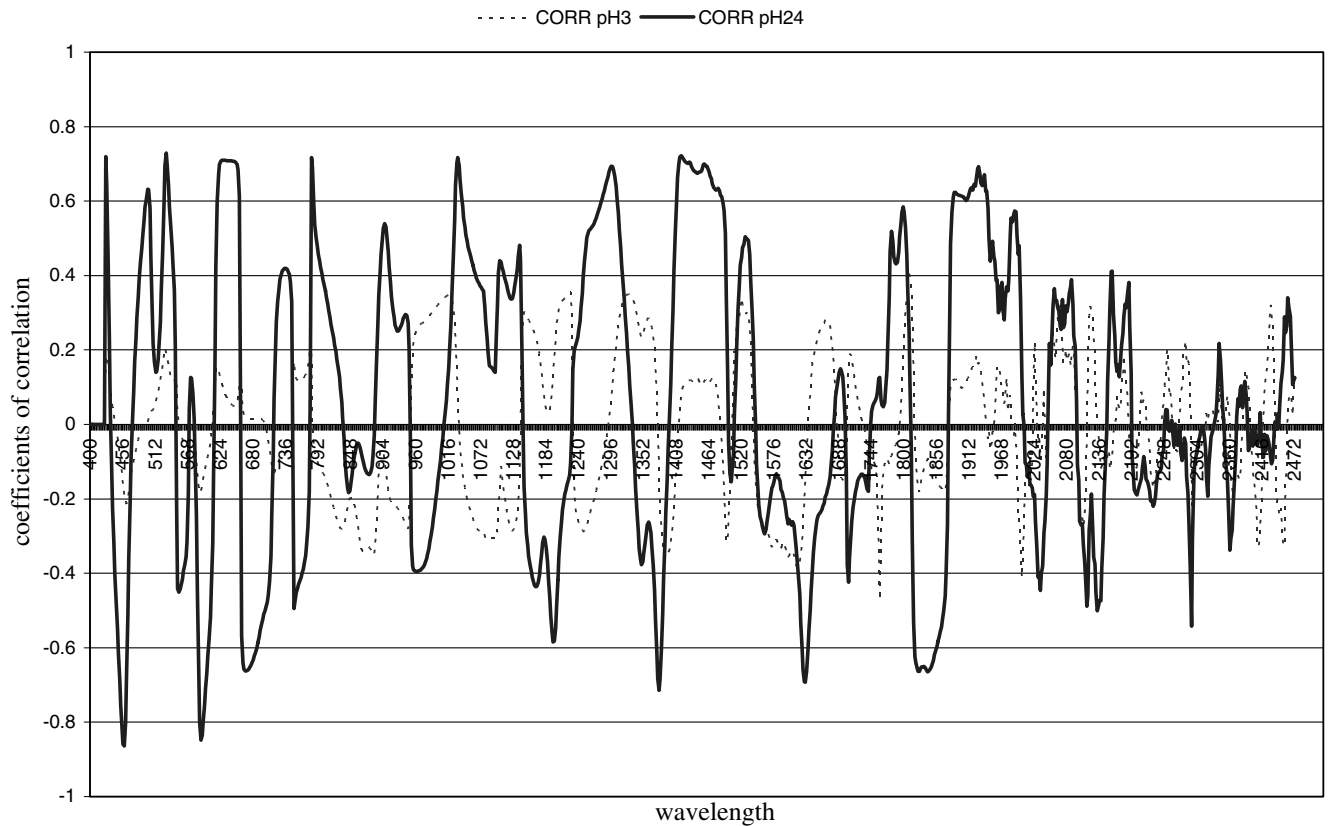

Fig. 3. Correlation coefficients $(R)$ between $\mathrm{pH} 3$ or $\mathrm{pH} 24$ and the absorbance data of the average second-order derivative spectra corresponding to the beef samples at day 1 post-mortem $(n=30)$.

In agreement with different authors (Meulemans, Dotreppe, Leroy, Istase, \& Clinquart, 2003; Leroy et al., 2003) CL parameter could not be accurately predicted by NIRS $\left(R^{2}=0.20, \mathrm{RPD}=1.01\right)$. However, important correlations between the absorbance in some regions and the CL parameter could be observed (Fig. 5). For example, absorbance data related to meat respiratory pigments at $530 \mathrm{~nm}$ (myoglobin), and $780 \mathrm{~nm}$ (deoxymyoglo- bin) seemed to explain somehow part of the variability related to the CL parameter. In addition, those areas related to the absorption of $\mathrm{C}-\mathrm{H}$ bonds in the fat fraction and $\mathrm{O}-\mathrm{H}$ bonds of water showed coefficients of correlation of near 0.60 with $\mathrm{CL}$ parameter. This is reasonable since water is the main fraction lost after cooking and water and fat fraction are negatively correlated in meat. 
Table 3

Prediction of technological characteristics of beef samples by near infrared reflectance spectroscopy

\begin{tabular}{lrllllll}
\hline Parameter & $n$ & $p$ & SEC & $R^{2}$ & SECV & 1-VR & RPD \\
\hline pH24 & 27 & 3 & 0.06 & 0.97 & 0.10 & 0.91 & 3.17 \\
CL & 99 & 1 & 0.07 & 0.20 & 0.08 & 0.02 & 1.01 \\
$L^{*} t 0$ & 108 & 5 & 1.00 & 0.85 & 1.16 & 0.80 & 2.22 \\
$a^{*} t 0$ & 104 & 2 & 1.04 & 0.29 & 1.09 & 0.23 & 1.14 \\
$b^{*} t 0$ & 109 & 3 & 0.63 & 0.49 & 0.75 & 0.27 & 1.17 \\
$L^{*} t 60$ & 109 & 4 & 1.19 & 0.82 & 1.36 & 0.75 & 2.07 \\
$a^{*} t 60$ & 100 & 2 & 1.22 & 0.35 & 1.28 & 0.29 & 0.90 \\
$b^{*} t 60$ & 99 & 4 & 0.95 & 0.51 & 0.99 & 0.46 & 1.37 \\
SL & 30 & 1 & 0.08 & 0.16 & 0.10 & 0.02 & 0.84 \\
WBSF & 112 & 5 & 2.30 & 0.65 & 2.67 & 0.53 & 1.46 \\
\hline
\end{tabular}

$n$ : number of samples; $p$ : number of PLUS factors in the equation; SEC: standard error of calibration; $R 2$ : coefficient of determination for calibration; SECV: standard error of cross validation; 1-VR: coefficient of determination for validation; RPD; ratio performance deviation calculated as SD/SECV.

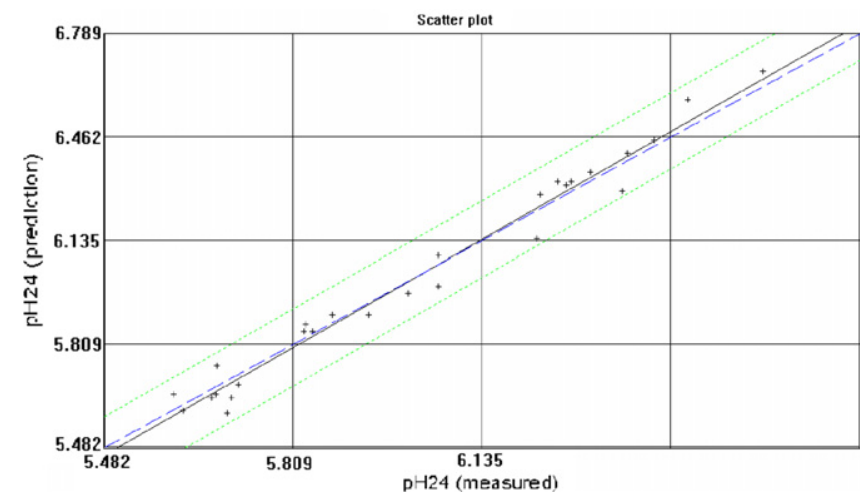

Fig. 4. Relationship between the $\mathrm{pH} 24$ reference data and those predicted by NIRS in meat samples $(n=30)$.
Regarding colour parameters, luminosity $L^{*} t 0$ (Fig. 6) and $L^{*} t 60$ (Fig. 7) showed the best predictions by NIRS $\left(R^{2}>0.80 ; \mathrm{RPD}>2.00\right)$. This is in agreement with the results reported by Leroy et al. (2003) in beef samples $\left(R^{2}=0.83\right)$. Liu et al. (2003) found poorer predictions of luminosity in beef samples because the visible region $(400-1080 \mathrm{~nm})$ was used to measure the spectra, whereas meat components responsible for $L^{*}$ are water and fat, which can be detected in the near infrared region. Indeed, the successful prediction of $L^{*} t 0$ and $L^{*} t 60$ achieved in the present study could be due to the good correlation between them and the intramuscular fat. In the present study intramuscular fat was not determined, but it is well known that this is one of the best parameters predicted using near infrared spectra of meat samples (Prieto, Andrés, Giráldez, Mantecón, \& Lavín, 2006).

On the other hand, $a^{*}$ (red-green) and $b^{*}$ (yellow-blue) parameters measured after 0 and 60 min of oxygenation could not be predicted by visible and near infrared spectroscopy $\left(R^{2}<0.60\right.$, RPD $\left.>0.90\right)$, almost certainly as a result of the time elapsed between the reference method (performed on unfrozen meat) and the spectra measurement (performed later on NIR samples which were frozen and thawed). During this period of time the proportions of respiratory pigments determining $a^{*}$ and $b^{*}$ values (myoglobin, oxymyoglobin and metmyoglobin) might well have been modified as a consequence of the freezing process, thus giving rise to a change in the colour of meat samples and hence decreasing the accuracy of prediction by visible and near infrared spectroscopy (Leroy et al., 2003). This statement is supported by the results obtained by Liu et al. (2003) in beef samples, who could predict $a^{*}$ and $b^{*}$ parameters with a high degree of accuracy $\left(R^{2}=0.90\right.$, 0.78 , respectively) due to absorbance of different forms of

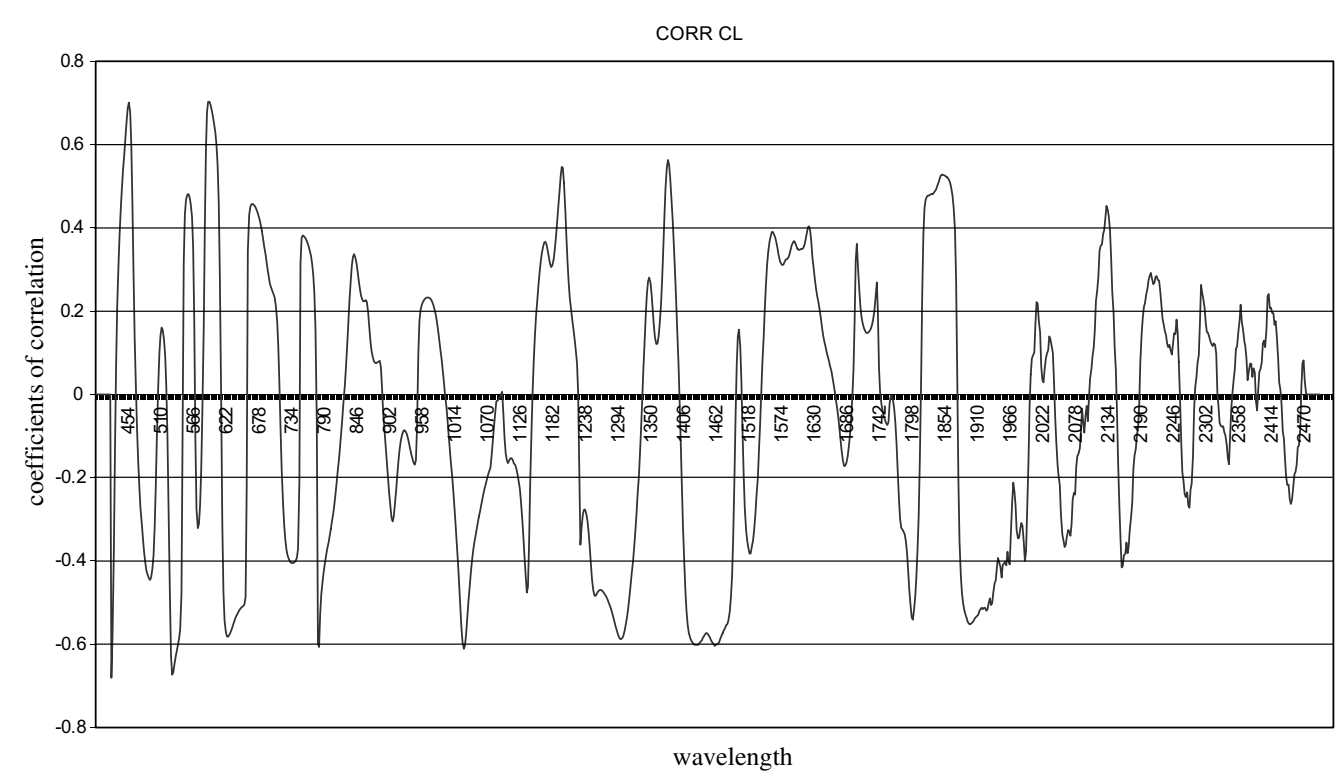

Fig. 5. Correlation coefficients $(R)$ between CL and the absorbance data of the average second-order derivative spectra corresponding to the beef samples $(n=120)$. 


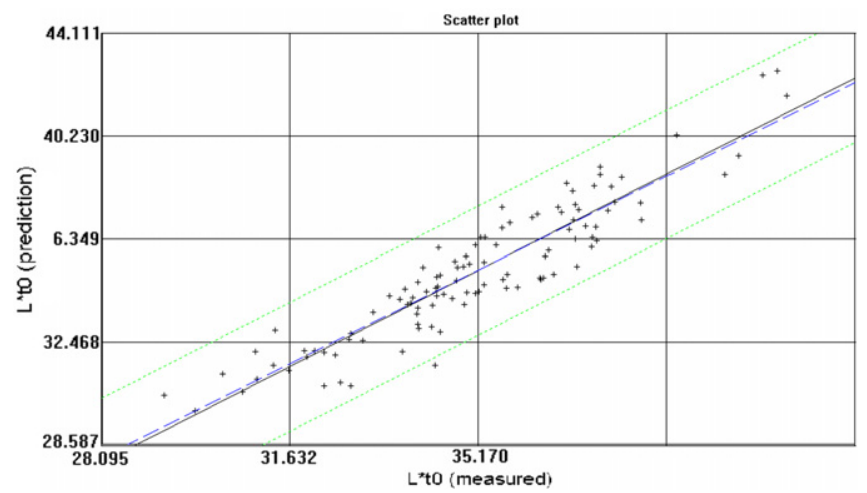

Fig. 6. Relationship between $L^{*} t 0$ reference data and those predicted by NIRS in meat samples $(n=120)$.

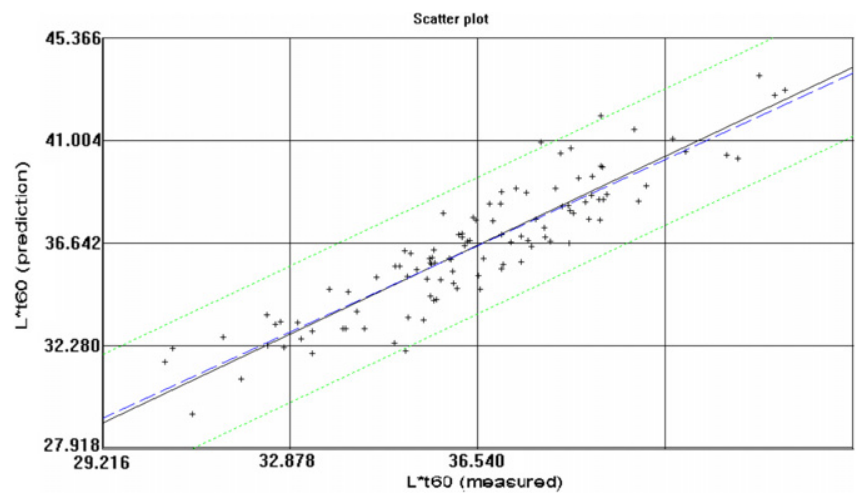

Fig. 7. Relationship between $L^{*} t 60$ reference data and those predicted by NIRS in meat samples $(n=120)$.

myoglobin in the visible region. Successful prediction of $a^{*}$ and $b^{*}$ probably requires simultaneous measurement of these parameters and the spectra, since colour changes can happen between them.

In spite of the poor results for SL $\left(R^{2}=0.16\right.$, RPD $=0.84)$, the statistics for WBSF $\left(R^{2}=0.65\right.$, $\mathrm{RPD}=1.46)$ could be considered as useful. These statistics are in agreement with the ones described by Byrne, Troy, Downey, and Buckley (1997), Park, Chen, Hruschka, Shackelford, and Koohmaraie (1998) and Rødbotten et al. (2000) showing $R^{2}$ values of $0.68,0.63$ and 0.67 , respectively. The different aging times considered in our study could have improved the variability of this parameter, an essential requirement for NIRS performance.

It should be stressed that direct comparison of prediction results with other studies is difficult for several reasons. For instance, meat samples are usually aged for different periods of time, sometimes frozen and thawed. Furthermore, the instruments used to perform the technological analysis also differ among studies, and the spectra are obtained in reflectance/transmittance modes often having quite different presentation geometry to the instrument, the radiation source and the detectors. Such operational constraints can profoundly affect performance (Swatland, 1995).
However, it must be pointed out that intact muscle samples with the complete organization of tissue unaffected were used in the present study so, possibly this fact is the reason why the obtained results are more accurately predicted than those previously described by other authors (Venel, Mullen, Downey, \& Troy, 2001; Liu et al., 2003).

\section{Conclusions}

Although the beef samples studied in this work arose from a small number of animals $(n=30)$ and muscle samples $(n=120)$, some conclusions can be drawn. The results obtained in this study suggest that visible and near infrared spectroscopy instruments (400-2500 nm) can accurately predict $\mathrm{pH} 24$ and $L^{*}$ parameters, and have a good potential to provide useful prediction of WBSF on intact beef muscle samples.

\section{Acknowledgements}

This work was carried out in collaboration of SAC (Aberdeen, Scotland), UTAD (Vila Real, Portugal) and ISA (Lisboa, Portugal) with financial support from PROGRAM AGRO (Ministério da Agricultura, Desenvolvimento Rural e Pescas; União Europeia, Fundos Estruturais).

\section{References}

Barlocco, N., Vadell, A., Ballesteros, F., Gallieta, G., \& Cozzolino, D. (2006). Predicting intramuscular fat, moisture and Warner-Bratzler shear force in pork muscle using near infrared spectroscopy. Animal Science, 82, 111-116.

Barnes, R. J., Dhanoa, M. S., \& Lister, S. J. (1989). Standard normal variate transformation and detrending of near infrared diffuse reflectance spectroscopy. Applied Spectroscopy, 28, 115-128.

Byrne, C. E., Troy, D. J., Downey, G., \& Buckley, D. J. (1997). Near Infrared spectroscopy as a meat quality indicator. In Proceedings 43th international congress of meat science and technology (pp. 644-645), 27 July - 1 August, Auckland, New Zealand.

Cozzolino, D., \& Murray, I. (2004). Identification of animal meat muscles by visible and near infrared reflectance spectroscopy. Lebensm.Wiss.u.-Technol., 37, 447-452.

Cozzolino, D., Barlocco, N., Vadell, A., Ballesteros, F., \& Gallieta, G. (2003). The use of visible and near-infrared reflectance spectroscopy to predict colour on both intact and homogenised pork muscle. Lebensm.Wiss. U.-Technol, 36, 195-202.

Cross, H. R., West, R. L., \& Dutson, T. R. (1981). Comparision of methods for measuring sarcomere length in beef semitendinosus muscle. Meat Science, 5, 261-266.

Dhanoa, M. S., Lister, S. J., Sanderson, R., \& Barnes, R. J. (1994). The link between multiplicative scatter correction (MSC) and standard normal variate (SNV) transformations of NIR spectra. Journal of Near Infrared Spectroscopy, 2, 43-47.

Downey, G., \& Hildrum, K. I. (2004). Analysis of meat. In C. A. Roberts, J. Workman Jr., \& J. B. Reeves III (Eds.), Near infrared spectroscopy in agriculture agronomy $n^{\circ} 44$ (pp. 599-632). Madison, WI, USA: American Society of Agronomy Inc., Crop Science Society of America Inc., Soil Science Society of America Inc.

Edney, M. J., Morgan, J. E., Williams, P. C., \& Campbell, L. D. (1994). Analysis of feed barley by near infrared reflectance technology. Journal of Near Infrared Spectroscopy, 2, 33-41.

Geesink, G. H., Schreutelkamp, F. H., Frankhuizen, R., Vedder, H. W., Faber, N. M., Kranen, R. W., et al. (2003). Prediction of pork quality 
attributes from near infrared reflectance spectra. Meat Science, 65, 661-668.

Guignot, F., Touraille, C., Ouali, A., \& Renerre, M. (1994). Relationships between post-mortem $\mathrm{pH}$ changes and some traits of sensory quality in veal. Meat Science, 37, 315-325.

Leroy, B., Lambotte, S., Dotreppe, O., Lecocq, H., Istasse, L., \& Clinquart, A. (2003). Prediction of technological and organoleptic properties of beef Longissimus thoracis from near-infrared reflectance and transmission spectra. Meat Science, 66, 45-54.

Liu, Y., Lyon, B. G., Windham, W. R., Realini, C. E., Pringle, T. D. D., \& Duckett, S. (2003). Prediction of color, texture, and sensory characteristics of beef steaks by visible and near infrared reflectance spectroscopy. A feasibility study. Meat Science, 65, 1107-1115.

Meulemans, A., Dotreppe, O., Leroy, B., Istase, L., \& Clinquart, A. (2003). Prediction of organoleptic and technological characteristics of pork meat by near infrared spectroscopy. Sciences des Aliments, 23, 159-162.

Monin, G. (1998). Recent methods for predicting quality of whole meat. Meat Science, 49, S231-S243.

Park, B., Chen, Y. R., Hruschka, W. R., Shackelford, S. D., \& Koohmaraie, M. (1998). Near infrared reflectance analysis for predicting beef longissimus tenderness. Journal of Animal Science, $76,2115-2120$.
Prevolnik, M., Candek-Potokar, M., \& Skorjanc, D. (2004). Ability of NIR spectroscopy to predict meat chemical composition and quality a review. Czech Journal of Animal Science, 49, 500-510.

Prieto, N., Andrés, S., Giráldez, F. J., Mantecón, A. R., \& Lavín, M. P. (2006). Potential use of near infrared spectroscopy (NIRS) for the estimation of chemical composition of oxen meat samples. Meat Science, 74, 487-496.

Quali, A., Lepetit, J., Touraille, C., \& Kopp, J. (1994). Cinétique d'attendrissage de la viande de veau. Viandes Produits Carnés, 15(3), 83-86.

Rødbotten, R., Nilsen, B. N., \& Hildrum, K. I. (2000). Prediction of beef quality attributes for early post mortem near infrared reflectance spectra. Food Chemistry, 69, 427-436.

Silva, J. A., Patarata, L., \& Martins, C. (1999). Influence of ultimate pH on bovine meat tenderness during ageing. Meat Science, 53, 453-459.

Swatland, H. J. (1995). On line evaluation of meat. Lancaster, PA, USA: Technomic Publishing Co.

Tornberg, E. (1996). Biophysical aspects of meat tenderness. Meat Science, 43, S175-S191.

Venel, C., Mullen, A. M., Downey, G., \& Troy, J. D. (2001). Prediction of tenderness and other quality attributes of beef by near infrared reflectance spectroscopy between 750 and $1100 \mathrm{~nm}$. Journal of Near Infrared Spectroscopy, 9, 185-198. 